\title{
Operatividade, imaginário e ethos na teoria da arquitetura
}

\author{
Paolla Clayr de Arruda Silveira*
}

\begin{abstract}
Resumo Neste trabalho são elencados elementos dialógicos da crítica operativa da historiografia a fim de levantar alguns fatores de importância para a discussão; balanceando alguns estudos sobre o ser humano e seu imaginário radical, onde acontecem as conexões da psique e seu eu histórico-social, assim como sua lida enquanto ser historiador e produtor de uma obra, que pressupõem um ethos, sua definição e ocorrência na relação discursiva dos textos escritos, através da mescla dos assuntos transdisciplinares na arquitetura e urbanismo enquanto campo de pesquisa.
\end{abstract}

Palavras-chave: historiografia, operatividade, história da arquitetura.

\section{Operatividad, imaginario y ethos en la teoría de la arquitectura}

Resumen En este trabajo se enumeran elementos dialógicos de la crítica operativa de la historiografía con el fin de plantear algunos factores de importancia para la discusión; equilibrando algunos estudios sobre el ser humano y su imaginario radical, donde se dan las provisiones de la psique y su yo histórico-social, así como su labor como historiador y productor de una obra, que presupone un ethos, su definición y ocurrencia en la relación discursiva de los textos escritos, a través de la mezcla de temas transdisciplinares en la arquitectura y el urbanismo como campo de investigación.

Palabras clave: historiografía, operatividad histórica, historia de la arquitectura.

\section{Operativity, imaginary and ethos in architecture theory}

\begin{abstract}
In this work, dialogical elements of the operational criticism of historiography are listed in order to raise some factors of importance for the discussion; balancing some studies on the human being and his radical imaginary, where the provisions of the psyche and his historical-social self take place, as well as his work as a historian and producer of a work, which presupposes an ethos, its definition and occurrence in the discursive relationship of the written texts, through the mix of transdisciplinary subjects, architecture and urbanism as the field of research.
\end{abstract}

Keywords: historiography, historical operativeness, history of architecture. 


\section{0 peratividade no mapeamento histórico}

O processo do registro histórico da arquitetura assemelha-se a um mapeamento das implicações historiográficas e socioculturais, que colaboram para o impacto na percepção e compreensão da arquitetura do passado. Dana Arnold (2004) diante dessa reflexão da construção histórica, coloca a arquitetura como um palimpsesto, com características que permitem diversas leituras, sendo um terreno a ser cruzado, e por isso, mapeado.

Nesse sentido, para decifrar ou buscar revelar os significados imbricados na linguagem histórica da arquitetura, dá-se por necessário abandonar o fato histórico que fala por si mesmo para visualizar o contexto temporal e intelectual, que implicará no modo de compreendê-lo.

O ato de abandonar requer, portanto, lançar mão do uso da teoria como lente de observação da historiografia das histórias dentro das obras e registros, buscando a revelação do que as histórias contadas sobre a arquitetura podem dizer sobre nós mesmos, além do suporte descritivo que as obras construídas possuem.

O espaço construído está imerso entre o espaço social e o espaço cultural, e é nesse espaço que estão elementos que enriquecem as teorias em volta das histórias e, através delas, iniciam-se as discussões da real perspectiva do passado e de como comportamentos encontrados na historiografia emergem pistas que uma sociedade, num campo discursivo tangente ao conceito de ethos.

A história se encontra como campo de ligação entre o passado e presente, através de um discurso colorido, como diz Arnold (2004), pelas modas intelectuais do presente, através de uma voz narrativa, e a escolha da narrativa é uma maneira de falar dada aos fatos.

A operatividade historiográfica surge como meio de juntar e separar arquivos, fatos e paradigmas teóricos para discutir como a força da história impactam na percepção da arquitetura do passado, mas vale ressaltar que fatos passados não estão acessíveis à inspeção imediata, e a forma de colocá-los à prova é através das evidências históricas, as pistas e vestígios. Dana Arnold (2004) e Walsh (1958) reiteram que se a história não tem evidências, passa a ser mera ficção.

* Paolla Clayr de Arruda Silveira é Arquiteta e Urbanista, Professora do Curso de Arquitetura e Urbanismo do Instituto Federal Fluminense, ORCID <https://orcid.org/0000-0001-5918-8069>.
O questionamento ao redor dessa análise está em perguntar como o historiador de arquitetura escreve os fatos em suas obras, visto que escreve aos olhos do presente em que está vivenciando, sujeito aos padrões sociais, culturais, intelectuais e tantas outras vertentes consideradas produtoras do caráter de qualquer sujeito, sendo esse o ponto em que o historiador impregna seus textos e discursos com minúcias que não são reais no passado que busca descrever, apresentar, etc. 
Giedion (1957) embasa esse pensamento ao afirmar que a história não é estática, mas dinâmica, e encontra-se em constante mudança a depender do ponto de observação de cada geração seguinte, sendo esse o padrão para afirmar que não existe um historiador objetivo, somente uma aparência de imparcialidade.

Não é possível abordar a história sem questionar o próprio discurso historiográfico, processo esse que seria a união entre um lugar, os procedimentos de análise e a construção de um texto, e fazer história é uma prática, nas palavras de Certeau (1982).

Os campos duros da ciência, ou seja, o discurso científico, atuam como validadores de determinado conteúdo, acenando para sua pertinência ou vulgarização, e é o discurso científico o verdadeiro destinatário de um livro de história, portanto, busca sempre se encaixar em métodos que o justifiquem, abrindo espaço para que resquícios do real se percam ou se impregnam na obra.

Certeau (1982) faz uma grande crítica à operatividade da historiografia, citando o lugar como produtor do estudo histórico, cabendo dizer que antes de saber o que a história diz sobre uma sociedade, é necessário saber como funciona dentro dela, e a pesquisa histórica está incluída neste lugar, estando na história a relação da linguagem com o corpo social. Quanto a essa linguagem que procede à história ressalta-se a articulação que o historiador provoca, civilizando a natureza, colonizando-a ou alterando-a, portanto, tem faces nos fatos que jamais serão demonstrados.

Assim, diante dessas colocações, os estudiosos da historiografia buscam formas para revelar as minúcias dentro das obras históricas, e nesse sentido, Bonta (1978) reafirma que nenhuma obra fala por si mesma, defendendo que as teorias são necessárias para verbalizar o significado e estabelecer outros cânones interpretativos, que não os mais usuais, que, no entanto, levariam tempo.

Assim, em seu trabalho, mencionou que o esforço deverá ser coletivo para que se criem as ferramentas com vistas às análises, citando inclusive a semiótica como abordagem, mas principalmente, por destacar que o tempo é fator importante no processo interpretativo. Passados quarenta anos de seu texto, ainda é um campo vasto esse lugar onde ocorrem as condutas sociais e a história.

Bonta (1978) também vai acrescentar à discussão o fazer investigativo dentro da historiografia arquitetônica ao relacionar os modos de interpretar, separando-os em debates pré-canônicos e canônicos. De maneira geral, analisar objetos antes de se tornarem canônicos leva a discursos provisórios que geram respostas individuais em cada sujeito e podem ser debatidos com outras reflexões individuais, ou seja, permite a cada pessoa seu próprio processo de construção particular.

Quando se interpreta um objeto cânone, em definitivo, a interpretação dá-se compartilhada com os demais sujeitos, de certa forma padronizada, uniformizada, não necessariamente criativa ou aberta a questionamentos.

Outrossim, Bonta (1978) expõe nesse contexto um princípio da constante "além da arquitetura" que será mencionada por Manfredo Tafuri (2011), onde o que importa é pensar a história para além da arquitetura, reconhecendo outras dimensões que 
influenciam sobre a construção histórica, sendo, portanto, a constante que atuará como mola propulsora dos momentos de ruptura do novo, numa frequente desmontagem do objeto de investigação.

A desmontagem do objeto se apoia na máxima de pensar o discurso como uma violência que fazemos às coisas, numa breve síntese das falas de Foucault, trazendo a perspectiva de Dana Arnold abordada em parágrafos anteriores, estando a história da arquitetura sempre aparecendo como fruto de uma dialética.

Na remontagem, segundo Tafuri (2011), o ato crítico da análise de uma obra é a recomposição dos fragmentos históricos, assim, atua no rompimento do círculo da linguagem e na recuperação da função da própria linguagem.

Em outro trabalho, Tafuri (2017) coloca dois elementos essenciais para a investigação da historiografia da arquitetura, como a mentalidade e a distância. A mentalidade, ou estrutura mental, precisa ser entendida em conformidade com determinado período; e a distância surge como fundamental para que o historiador examine o trabalho atual criando uma distância artificial. Para o autor, o caminho para nos distanciarmos do tempo presente e da perspectiva do momento é confrontar as diferenças do passado.

\section{Imaginário radical do historiador}

Para Castoriadis (1982, p. 90), o homem é criação de uma formação exagerada da imaginação: "o que faz a essência do homem, precisamente, é a imaginação criadora". O imaginário, antes de tudo e de mais nada, segundo Castoriadis (1982, p.154), é "faculdade originária de pôr ou dar-se, sob a forma de representação, uma coisa é uma relação que não são (que não são dadas na percepção) ou nunca foram".

O imaginário radical é fonte criadora tanto da psique quanto do social-histórico, e estas não são incomunicáveis nem estáticas, embora a dimensão psíquica, a todo tempo, tenha a sua participação ocultada na criação social. A psique se "manifesta tanto em forma de sonhos ou doenças psíquicas como também em alterações, ainda que lentamente, do imaginário social", que, por sua vez, possibilita que a psique existe, "porque é na dimensão social-histórica que se dá um sentido para a vida. A psique só pode existir socializada". (PERRUSI, 1999, p. 32)

Silveira (2015) descreveu em um trabalho sobre memória e criatividade dentro da arquitetura que o imaginário radical se refere ao fluxo constante de criação, mas os estudiosos de filosofia deram ênfase à dimensão psíquica, reduzida ao papel subalterno ou meramente auxiliar, instrumental. A arte surge então como gênero indiscutível ao elevar a importância de se dar espaço ao "inimaginável", ao "infrapensável", "suprapensável", onde há um desejante que cria, imagina. Na arte, assim como na arquitetura, a imaginação é fonte constante de criação.

Gumbrecht (2010) fez uma análise sobre essa redução do imaginário radical na história e buscou demonstrar alguns problemas referentes às "oscilações tensas" e "não resolvidas" entre linguagem e presença em seus aspectos de polissemia. 
Neste ponto surgem os questionamentos sobre a influência da emoção (seja pela sensação, imaginação ou memória) na tomada de decisões, algo aparentemente racional. Será que no momento de escrever é a memória do historiador que determina a resposta? Ou há uma expressividade puramente livre? Pode haver um comportamento puramente racional sem a influência da emoção?

Simmel (2002, p. 325) expressa que "a maior parte dos produtos de nossa criação espiritual contêm no interior de sua significação uma certa quota que nós não criamos (...) que pode ser extraído por outros sujeitos, mas que nós mesmos não introduzimos", o que tem muita relação com as colocações de Juan Pablo Bonta e Manfredo Tafuri, apresentadas anteriormente.

A posição do historiador, de acordo com Castoriadis, qualquer que seja o campo considerado, deve ser a de sustentar uma entidade histórica, e Ribeiro $(2016$, p. 61) bem sintetiza esse pensamento, ao dizer que o tema do historiador "faz parte de um todo, em que ele normalmente se depara com o que lhe interessa, porém além desse interesse, existem outras coisas envolvidas que escapam do seu controle".

É no imaginário radical que a análise histórica não é livre, portanto, e aqui Castoriadis se relaciona intensamente com Certeau e Giedion, afirmando que:

Nenhum artifício filosófico ou epistemológico (...) será capaz de eliminar o ser próprio do objeto social-histórico. (...). Os que não podem ver isso deveriam se abster de falar em sociedade e em história e ocupar-se de matemática, cristalografia ou entomologia (evitando cuidadosamente, inclusive nesses campos, as questões teóricas). (CASTORIADIS, 1985, p. 23)

Atualmente a história não credita "o autor que conseguiu livrar-se de sua subjetividade ao construir sua narrativa (mesmo porque tal seria impossível), mas sim aquela na qual o autor soube perceber e usar a seu favor a inevitável subjetividade de sua escrita", como contextualiza Espig (2004, p. 54) em seu trabalho sobre o imaginário na produção histórica contemporânea.

Acerca das fontes, "percebê-las enquanto representação construída pelos agentes históricos pode trazer um maior refinamento à análise e mesmo uma maior honestidade intelectual".

Ao estabelecer uma "identidade" histórica para uma sociedade, bem como códigos de comportamento coletivamente aceitos em determinada época, o imaginário assume uma realidade específica, não podendo mais ser percebido tão somente como um tipo de "adorno" de relações econômicas, políticas, etc., como se estas fossem as únicas "reais" (BACZKO, 1991, p. 14).

As lutas e conflitos estabelecidos em torno destes bens simbólicos comprovam, segundo Baczko, seu caráter imaginário, mas não ilusório. Portanto, para Castoriadis o imaginário radical é fonte de criação incessante e a realidade não é outra coisa senão o imaginário efetivado, sob a qual se erige a história, a realidade, a racionalidade, enfim, a sociedade.

De modo a equilibrar as reflexões, está no ponto médio o caráter simbólico, pois "o imaginário deve utilizar o simbólico, não somente para exprimir-se, o que é óbvio, 
mas para existir, para passar do virtual a qualquer coisa mais" (Castoriadis, 1982, p. 154). Como também pensam Leach (1992) e Mauss (2003), o simbólico é o elemento de mediação entre o real e o imaginário, o racional e o sentimental.

\section{O conceito de ethos na historiografia}

Sob o arcabouço teórico da Análise do Discurso Francesa, o conceito de ethos se refere à criação de uma imagem de si por meio do discurso. Deste modo, ao afirmar que um enunciador pretende refletir uma autoimagem, significa também afirmar que o discurso traz consigo pistas do enunciador e do coenunciador, presentes aqui como os que interagem no processo discursivo.

Roland Barthes (1970, p. 315) define o ethos como "os traços de caráter que o orador deve mostrar ao auditório (pouco importando sua sinceridade) para causar boa impressão: é o seu jeito [...]. O orador enuncia uma informação e ao mesmo tempo diz: sou isto, não sou aquilo". É nesse processo de autoproclamação que o historiador se apresenta através da obra, visto que, segundo Maingueneau (2005), não existe um ethos preestabelecido, mas, sim, construído no âmbito da atividade discursiva.

Nessa perspectiva, a imagem de si é um fenômeno que se constrói na instância enunciativa e se mostra pelo seu discurso, podendo estar presente num texto escrito ou oral, que neste trabalho referenciamos às obras literárias de teoria e história da arquitetura. Amossy (2005) contribui que o enunciador deve se conferir, e conferir a seu destinatário, certo status para legitimar seu dizer: ele se outorga no discurso uma posição institucional e marca sua relação com um saber.

É possível perceber, portanto, que o papel do historiador está imerso em ethos, que podem ser, propositalmente, incluídos por ele nos trabalhos, a fim de passar uma determinada simbologia para os leitores (ethos prévio); ou, como também pode ocorrer, algumas características do autor impregnam o trabalho escrito sem que perceba, mas que os leitores podem, por conseguinte, recuperar e construir uma imagem dessa autoria.

A constituição do ethos, portanto, será realizada a partir de uma relação entre as escolhas do enunciador (de acordo com suas visadas) e o seu ethos prévio, que é composto pela representação coletiva e pelos estereótipos que o leitor/ouvinte produz a respeito.

Como explica Maingueneau (2013, p. 108), "o ethos implica, com efeito, uma disciplina do corpo apreendido por intermédio de um comportamento global', sendo representados pelo o que o autor chama de "conjunto difuso de representações sociais valorizadas e desvalorizadas, sobre as quais se apoia a enunciação", e esses estereótipos que cada sujeito carrega circulam em diversos campos culturais, como a literatura, o cinema, as fotos, a publicidade, etc. Amossy (2005) relembra que, conforme propõe Benveniste, ao construir um enunciado, ou seja, ao colocar a língua em funcionamento, o enunciador se coloca como sujeito e inscreve sua subjetividade.

De acordo com Heine (2007, p. 41): 
o ethos se refere a textos orais e escritos, em que os enunciadores fornecem uma imagem de si através do discurso. Assim, dizer que os participantes do discurso criam uma imagem de si através dele, significa também afirmar que o discurso carrega as marcas do enunciador e do coenunciandor, entendidos como aqueles que interagem no processo discursivo.

Knauss (2008, p. 146) apontou a escrita da história como um fato moral, diante das particularidades existentes na figura do historiador e das reverberações de sua produção, e afirma que "a própria condição do profissional de História é interrogada pelo seu posicionamento moral no espaço público". Portanto, a relação entre ética e conhecimento aponta para uma das dimensões que constitui um ethos particular em que os pares se reconhecem", que para Maingueneau (2013), toda fala procede de um enunciador encarnado, e Amossy (2005, p. 142) completa que "para todas as abordagens que valorizam a eficácia da fala, o ethos não é somente uma postura que manifesta o pertencimento a um grupo dominante, ele é uma imagem de si construída no discurso que influencia opiniões e atitudes". Ou seja, mesmo quando escrito, um texto é sustentado por uma voz - a de um sujeito localizado para além do texto.

Nesse assunto, José Luiz Fiorin (1996) diz que no âmbito da linguagem, é o discurso que pertence à ordem da História, e não o sistema, diante da própria essência instável da História, que não condiz com a ideia de um certo equilíbrio sistêmico, mas, ao contrário, está relacionada às características da singularidade enunciativa. Seria a partir da enunciação, na medida em que ela temporaliza, espacializa e actorializa a linguagem, que se processa a passagem do sistema ao discurso - o homem, segundo o autor, é colocado na história pela enunciação, e o discurso, sendo, neste sentido, da ordem da História, pode mudar o sistema.

\section{Reflexões possíveis: paralelos entre operatividade, imaginário e ethos}

A transdiciplinaridade acontece "quando as fronteiras das "disciplinas se tornam móveis e fluidas num permeável processo de fusão" (FIORIN, 2008, p. 38). É transdisciplinar uma poética da ciência. "Na poesia, percebem-se analogias, observam-se correspondências, não se respeita autoridade dos códigos, das estruturas, da tradição, dos significados, do discurso. (...) É domínio da audácia, que leva a examinar todo o conhecimento" (FIORIN, 2008, p. 38).

Numa gota de audácia, portanto, pretendeu-se nesse ensaio um percurso transdisciplinar para observar o fazer histórico dentro da arquitetura e, através de alguns questionamentos sobre a historiografia, entender as críticas possíveis para desvendar algumas pistas deixadas pelos enunciadores em seus discursos textuais, pistas estas que sofreram influências da emoção criativa do autor, mescladas ao processo de escolhas e tomada de decisão pelo seu caráter de imaginário radical, na filosofia. Para Cohen (2011, p. 46), "essa admissão seletiva tende, com efeito, a uma espécie de falsificação narrativa e a uma fixação fetichista em figuras ou edifícios".

Alguns estudiosos da historiografia da arquitetura cunham as teorias como lente de análise para esses objetos, entendendo que o autor se prepara através de uma autoimagem linguística, de referências intencionais, outras subjetivas e tantas mais que 
fogem ao seu controle e permitem, assim, elementos de ethos discursivos que dizem os caracteres relevantes sobre a preparação de suas obras, cabendo a oportunidade de assumir os locutores como agentes históricos dentro do conjunto difuso das representações sociais a que estão submetidos, engajados, etc.

A história dinâmica é aliada à imaginação criadora, essência do ser humano, com faces que se refazem constantemente, seja através do ethos e sua necessidade de espalhar simbologias aos leitores a fim de significar seu conteúdo, quanto no papel de mediação assumido pela simbologia na relação entre real e imaginário, colocando a história como imaginário efetivado através desses conceitos simbólicos.

O trabalho do historiador, de certa forma, necessita da desconstrução, na busca de minúcias da forma de fazer a história da arquitetura, sendo talvez o momento o fator capaz de explicar a obra.

Para construção do objeto, na perspectiva transdisciplinar, outros temas cruzam a trajetória da pesquisa, de modo a participar de um jogo entre os elementos construtores do texto, cunhando pressupostos teóricos e abordagens metodológicas emprestadas de outros campos para além da arquitetura, transdisciplinares, afinal, o papel histórico ou o desenvolvimento histórico se faz segundo uma significação possuída por quem fala, altamente criativo, imaginário, histórico, socializado e culturalmente performático.

Nesse sentido, Pereira (2014, p. 202) expõe essa transdisciplinaridade como "formas que se agregam para se constituir de modo denso em certas zonas, fluído e esgarçado em outras, se consolidando ou se diluindo a partir da interação de umas com outras ou francamente em situação de isolamento".

Assim, os questionamentos dentro da temática irão exigir o aprofundamento nas camadas de atores (enunciadores) e vozes (discursos) atuantes no campo cultural (discursivo). Como pontua Pereira (2014, p. 238), "o campo intelectual dos pesquisadores que praticam hoje a história de cidades ou da arte, e com elas ou a partir delas a história da arquitetura e/ou do urbanismo, se organizou em diferentes temporalidades e arranjos", demandando um verdadeiro processo exploratório e além-mar.

A partir desse momento, as diferentes visões de história e sobre a história colidem ou são preservadas, daí as leituras e interpretações de obras e trajetórias se completam ou se hibridizam, se organizando em zonas que sinalizam as potencialidades ou os desafios a serem enfrentados. Para Pereira (2014), ao pesquisador da historiografia cabe uma autoanálise sobre suas formas moventes, seus estudos e construções, afinal, é o tempo que "insufla" tanto a história quanto a arquitetura e suas práticas.

A definição do enquadramento da história da arquitetura "se dá dentro de uma relação dialética entre texto e imagem que remonta à própria definição da arquitetura como arte do disegno", como coloca Gonçalves (2010). Cabe assim ao historiador transformar um fato em fato histórico, "captando a configuração em que sua própria época entrou em contato com uma época anterior", explica Benjamin (1987). A história, assim como a arquitetura da cidade, também está sempre no presente.

Enfim, provocar os questionamentos em torno do fazer historiográfico em arquitetura e, baseado nos interesses da análise do discurso e da filosofia, mostrar o caráter complexo 
que a história possui, demonstra a transdisciplinaridade como uma possibilidade dialógica dentro desse campo. Nos ensinamentos de Morin (2005), a teoria da complexidade trabalha com o conceito do ser vivo instável (talvez o historiador?) e imprevisível (como a própria história?), mais aberto e criativo, uma imagem inovadora da natureza e da sociedade (proposital? ou espontânea?), que está contido no conceito da transdisciplinaridade.

E o que é o discurso senão transdisciplinaridade na sua forma mais pura?

\section{Referências bibliográficas}

AMOSSY, Ruth. (Org) Imagens de si no discurso: a construção do ethos. São Paulo: Contexto, 2005.

ARNOLD, Dana. Reading architectural history. Londres: Taylor \& Francis e-Library, 2004.

BACZKO, Bronislaw. Los imaginários sociales: memorias y esperanzas coletivas. Buenos Aires: Ediciones Nueva Visión, 1991.

BARTHES, Roland. A atividade estruturalista. In: Crítica e verdade. Trad. Geraldo Gerson de Souza, Editora Perspectiva: São Paulo, 1970.

BENJAMIN, Walter. Sobre o conceito de história. In: Obras escolhidas. Vol. 1. Magia e técnica, arte e política. Ensaios sobre literatura e história da cultura. São Paulo: Brasiliense, 1987.

BONTA, Juan Pablo. Sistemas de significación en arquitectura. Barcelona: Editorial Gustavo Gili, 1978.

CASTORIADIS, Cornelius. A instituição imaginária da sociedade. Trad. Guy Reynaud. Rio de Janeiro: Paz e Terra, 1982.

CASTORIADIS, Cornelius. A experiência do movimento operário. São Paulo: Brasiliense, 1985.

CERTEAU, Michel de. A Operação Historiográfica. In: A Escrita da História. Rio de Janeiro: Forense-Universitária, 1982.

COHEN, Jean-Louis. Da afirmação ideológica à história profissional. In: Desígnio. v. 11/12. Março de 2011. São Paulo: FAUUSP, 2011.

ESPIG, Márcia Janete. O conceito de imaginário: reflexões acerca de suas reflexões acerca de sua utilização pela História. In: Textura, v. 1, n. 9, nov. 2003 a jun. 2004, p. 49-56. Canoas: Ulbra, 2004. Disponível em: <http://www. periodicos.ulbra.br/index.php/txra/article/ view/701>. Acesso em 8 jan. 2021.

FIORIN, José Luiz. As Astúcias da Enunciação - as categorias de pessoa, espaço e tempo. São Paulo: Ática, 1996.

FIORIN, José Luiz. Linguagem e interdisciplinaridade. In: Alea, v. 10, n.1, jan. a jun. 2008. Rio de Janeiro: UFRJ, 2008. Disponível em: <https://doi.org/10.1590/S1517-106X2008 $000100003>$. Acesso em 7 jan. 2021.

GIEDION, Sigfried. History and the Architect. Journal of Architectural Education, v. 12, $\mathrm{n}^{\circ} 2$. Londres: Taylor \& Francis, 1957.

GONLÇAVES, Denise. Uma história da historiografia da arquitetura. In: ArtCultura, Uberlândia, v. 12, n. 20, p. 95-115, jan.-jun. 2010. Disponível em: <http://www.seer.ufu.br/index.php/ artcultura/article/download/11309/6748/>. Acesso em 16 mai. 2021.

GUMBRECHT, Hans Ulrich. Produção de presença: o que o sentido não consegue transmitir. Trad. Ana Isabel Soares. Rio de Janeiro: EDIPUC-Rio, 2010. 
HEINE, P. V. B. O ethos e a intimidade regulada: especificidades da construção da construção do ethos no processo de revelação da intimidade no blogs pessoais. Dissertação de Mestrado. Salvador, Instituto de Letras UFBA, 2007

KNAUSS, Paulo. Uma história para o nosso tempo: historiografia como fato moral. História Unisinos, vol. 12, n. 2, maio/agosto, 2008, p. 140-147.

LEACH, Edmund. Cultura e comunicação. Lisboa: Edições 70, 1992.

MAUSS, Marcel. Sociologia e Antropologia. São Paulo, Cosac \& Naify, 2003.

MAINGUENEAU, D. Ethos, cenografia, incorporação. In: AMOSSY, Ruth (Org). Imagens de si no discurso: a construção do ethos. São Paulo: Contexto, 2005.

MAINGUENEAU, D. Análise de textos de comunicação. São Paulo: Cortez, 2013.

MORIN, Edgar. Introdução ao pensamento complexo. Porto Alegre: Sulina, 2005.

PEREIRA, Margareth da Silva. O rumor das narrativas: A história da arquitetura e do urbanismo do século XX no Brasil como problema historiográfico. In: Redobra, ano 5, n. 13. Salvador: UFBA, 2014. Disponível em: <http://www.redobra.ufba.br/wp-content/ uploads/2014/10/ RD13_D03_O-rumor-das-narrativas.pdf>. Acesso em 10 jan. 2021.

PERRUSI, Martha. Aspectos da criação no pensamento de Castoriadis. In: Symposium. Ano 3. Número Especial, junho de 1999. Disponível em: <https://www.maxwell.vrac.puc-rio. br/2891/2891.pdf>. Acesso em 7 jan. 2021.

RIBEIRO, A. I. M. A experiência do movimento operário. In: Pro-Posições, v. 1, n. 1, p. 60-66. Campinas: Unicamp, 2016. Disponível em: <https://periodicos.sbu.unicamp.br/ojs/ index. php/proposic/article/view/8644513>. Acesso em 8 jan. 2021.

SILVEIRA, Paolla C. de A.; NASCIMENTO, G. do. Memória ou criação espontânea?. In: Revista do Colóquio, v. 5, n. 9, p. 128-140. Vitória: Colartes, 2015. Disponível em: <https://periodicos .ufes.br/colartes/article/view/11449>. Acesso em: 7 jan. 2021.

SIMMEL, Georg. Sobre la aventura. Barcelona: Península, 2002.

TAFURI, Manfredo. Arquitetura e historiografia: Uma proposta de método. In: Desígnio. v. 11/12. Março de 2011. São Paulo: FAUUSP, 2011.

TAFURI, Manfredo. There is not criticism, only history. Reading Design, 2017. Disponível em: <https://www.readingdesign.org/there-is-no-criticism>. Acesso em 07 jan. 2021.

WALSH, W. H. Uma introdução à filosofia de história. Londres: Hutchinson University Library, 1958. 